Journal of Business \& Management (COES\&RJ-JBM)

ISSN (E): 2306-7179 ISSN (P): 2306-8043

Publisher: Centre of Excellence for Scientific \& Research Journalism, COES\&RJ LLC

Online Publication Date \& Issue: 1st Jan. 2020, Vol.8, No.1, January 2020

https://doi.org/10.25255/jbm.2020.8.1.1.19

\title{
The Effect of Intellectual Capital on Competitive Advantage in the Jordanian Telecommunication Sector \\ Raed Kareem Kanaan
}

Amman Arab University, Jordan, rk@aau.edu.jo

Ulya Nawaf Obeidat

Department of Business Management, University of Jordan, Amman, Jordan, youlia_obeidat@hotmail.com

Bader Yousef Obeidat

Faculty of Business and Law, The British University in Dubai, Department of

Business Management, The University of Jordan (Unpaid Leave),

b.obeidat@ju.edu.jo

Mohammad Orsan Al-Zu'bi

Department of Business Management, University of Jordan, Amman, Jordan, m.alzoubi@ju.edu.jo

Mohammd Abuhashesh

E-Marketing and Social Media Department, Princess Sumaya University for

Technology (PSUT), Amman, Jordan, m.abuhashesh@psut.edu.jo

\section{Abstract:}

This paper sought to examine the effect of intellectual capital on competitive advantage in the Jordanian telecommunication sector. Indeed, intellectual capital is generally assumed to be an important aspect of the organization and one of the most conducive to innovative activity and unrestrained competition. The paper finds that the tripod of intellectual capital, namely, human capital, structural capital, and relational capital has a significant influence on achieving a competitive advantage. Among these three dimensions, relational capital is the most influential component in enhancing the competitive advantage. Considering these results, the research presented many recommendations for future research, the most important ones is implementing this study on other sectors, resort to multi-method of data collection, and the use of probability sampling techniques.

Keywords:

Intellectual Capital, Competitive Advantage, Telecommunication Sector, Jordan Citation:

Kanaan, Raed Kareem; Obeidat, Ulya Nawaf; Obeidat, Bader Yousef; Al-Zu'bi, Mohammad Orsan; Abuhashesh, Mohammd (2020); The Effect of Intellectual Capital on Competitive Advantage in the Jordanian Telecommunication Sector; Journal of Business \& Management (COES\&RJ-JBM) Vol.8, No.1, pp.1-19, https://doi.org/10.25255/jbm.2020.8.1.1.19. 


\section{Introduction}

In the presence of a hyper competitive environment, intellectual capital has been drawing more attention than ever before in recent years. Intellectual capital consisting of human, relational, and structural capital is widely recognized as an important contributor to achieve better economic growth (Wang, et al., 2014). Moreover, it is increasingly being considered by both scholars and practitioners as a major factor to gain a competitive advantage for knowledge organizations (Chahal and Bakshi, 2014; Karajeh and Maqableh, 2014; Maqableh, et al., 2015; Abualoush et al., 2018a,b). Amiri, et al. (2010) postulated that intellectual capital is one of the main organizational capabilities that have a positive impact on competitive advantage. Barney (1991) claims that organizations that possess and exploit resources and capabilities that are valuable, rare, inimitable, and organizational supported will be in a better competitive position.

Likewise, Newbert (2008) has linked the organizational resources and capabilities with a competitive advantage. In a narrower business context, resources refer to the basic building block that can be divided into tangible and intangible assets (Masa'deh, et al., 2015; Wheelen, et al., 2015) whereas capabilities mean the organization's ability to deploy and combine those resources to enhance the productivity and accomplish the strategic goals (Makadok, 2010). Therefore, the combination of intangible resources and capabilities in a way that enhance the ability to exploit market opportunities help an organization to establish and sustain a core competency in the form of competitive advantage (Chahal and Bakshi, 2015). Intellectual capital has become widely acknowledged as knowledge assets within an organization. Competitive advantage will not be sustainable unless an organization uses these assets effectively and efficiently. Accordingly, competitive advantage does not only occur from producing product and services to the customers, but also from the resources to produce them (Porter, 2008; Abuhashesh e al., 2019a, b).

\section{Literature Review}

Currently, the quest for a sustainable competitive advantage has received a remarkable attention by scholars at different fields in general, and scholars at strategic management in particular. Moreover, it is necessary for any organization to seek toward building a competitive advantage that is difficult to be imitated by competitors. In fact, obtaining a superior competitive position can be occurred through an effective utilizing of the firm's tangible and intangible resources. Due to the economic issues in the business environment, intellectual capital was considered as an opportunity for an organization to obtain a competitive edge (Al-Dmour, et al., 2015; Chahal and Bakshi, 2015). 


\subsection{Intellectual Capital}

Several definitions have been proposed to conceptualize intellectual capital. Hall (1992) posited that intellectual capital is a value driver that transforms production resources into valuable assets. Stewart (1997) referred to intellectual capital as the combination of everything in an organization knows that grants it a competitive advantage. Intellectual capital can be also defined as composed of the human aspect that consists of knowledge, experience, and skills of employees, and the organizational aspect that involves the knowledge resources stored in databases, systems, culture, and philosophy. Marr (2004) viewed intellectual capital as the collection of knowledge resources that are the premise behind giving an organization a competitive edge.

Subramaniam and Youndt (2005) claimed that intellectual capital is the combination of knowledge used in firm's operations to occupy a competitive position. This definition is consistent with another definition developed by Sofian (2004) who stated that intellectual capital is the interrelationship between professional knowledge and skills, goal relationships, and technological capabilities that enhance its competitive position. The European Commission (EC) (2006a) considered intellectual capital as the sum of human, structural, and relational resources that are related to the external ties of an organization such as with customers, suppliers, and other stakeholders. Intellectual capital as a merged of intelligence, wisdom, flexibility, distinctive capabilities, entrepreneurship, and creativity that are needed to succeed in progressively competitive global economy where technology and knowledge lead (Manzaneque, et al., 2017). Indeed, it has been observed that the tradition view toward the intellectual capital has been dramatically changed. These changes occurred due to the presences of such forces like the financial crisis that take place at the end of 2007. As well as, the shortening in the product life cycle the puts organizations on a jeopardy to be driven out of the market. Accordingly, organizations should pay much attention on exploiting the resources especially the tacit resources as intellectual capital and fit with the market demands.

In todays' business environment, the concept of intellectual capital has been much concerned by scholars. Rodrigues and Romero (2015) conceived that intellectual capital is the interconnectedness among human capital (e.g. Skill, experience, competences, and knowledge), structural capital (e.g. organizational processes, software databases, and business processes), and relational capital (e.g. customers, suppliers, creditors, investors, and other stakeholders) that create value for an organization. Dženopoljac (2016), Shed the light on the nature of intellectual capital since it is considered as an opportunity to affect the firm's performance if the managers utilize it. Noticeably scholars from different majors focus on conceptualizing intellectual capital as consisting of human, 
relational, and structural capital. In one way or another, these three aspects are interconnected to represent the intellectual capital (Chahal and Bakhshi, 2015).

\subsection{Dimensions of Intellectual Capital}

In fact, it has been asserted that intellectual capital refers to the knowledge capital. Regarding the conceptual dimensions of intellectual capital, this study follows the framework that views intellectual capital as a synergic set of human capital, structural capital, and relational capital.

\subsubsection{Human Capital}

Human capital is considered as a pivotal aspect that drives the other aspect of intellectual capital ( $\mathrm{Li}$ and Chang, 2010). Human capital is the organizational knowledge owned by employees but does not stay in the organization when they go home. Moreover, human capital is the professional competences, employees' skills, and leadership abilities that add value to the organizational processes. In this context, human capital is considered a key element to gain a competitive edge (Mehralian, et al., 2013). Human capital refers to the knowledge, experience, and capabilities that employees bring to the organization. According to Alwert (2006) he asserted that human capital covers the knowledge, skills, and motivation of employees that can be taken into home or to the next employer. Rocha (2012) developed a comprehensive description of human capital where it is defined as a combination of skills, competences, talents and know-how, ethics, values, and attitudes of both employees and managers. Human capital is also referred to the implicit knowledge that is deeply rooted in the employees (Kamukama, 2013; Wang, et al., 2014).

\subsubsection{Structural Capital}

Structural capital (also called the organization capital) concerns with the mechanisms and structures of an organization which remarkably enhances its innovative abilities. Hence, making it a vital organizational source. The distinguishing feature of structural capital is that it remains in the organization even when employees leave it (Edvinson, 1997). Moreover, structural capital is considered as the backbone of human capital to improve the employees' productivity. The premise behind this argument is that structural capital acts as a supportive infrastructure of human capital by providing employees with the necessary skills to invest their capabilities.

Regarding its definition, academic scholars have developed several definitions for structural capital. For instance, Bontis (1998) defined structural capital as non-human warehouses that contain the databases, organizational structure, work manuals, strategies, procedures, and any other thing whose value to the organization is greater than its material value. In a similar vein, structural capital is referred to the organizational storehouses that include its culture, policies, 
databases, information systems, patents, copyrights, and so on (Sharabati, et al., 2013). It is also described as the reflection of organizational knowledge in terms of technologies, patents, work processes, and cultures (Dahiyat, et al., 2014). As a conclusion, structural capital can be referred as knowledge created by an organization (Obeidat, et al., 2017).

\subsubsection{Relational Capital}

At its core, relational capital concerns with the deployment of knowledge and relationships through social structure (Hsu and Wang, 2012). Relational capital revolves around linking the internal intellectual resources with the external stakeholders such as customers and investors, Thus, it enhances the organization's ability to generate value (Wang, et al., 2014). Indeed, since relational capital stems from such norms as collaboration, communication, and sharing of information, it tends to remain in the organization regardless the changes the individual activities (Putnam, 1995).In addition, , relational capital considered as the knowledge that is utilized by the collaboration among individuals and their external relationships. It is also referred to the knowledge embedded in relationships with the organization's stakeholders that affect its life (Dahiyat, et al., 2014).

\subsubsection{Competitive Advantage}

Barney (1991) stated that competitive advantage is the development of a value creating strategy that cannot be implemented by any other competitors simultaneously. He further suggested that organization is said to have a sustainable competitive advantage when it is able to develop a value creating strategy that cannot be implemented, nor duplicated by current or potential competitors. Ma (2004) defined competitive advantage as the set of physical and financial resources that are effectively utilized. According to Grimaldi, et al. (2012) competitive advantage is the result of integration between external opportunities and internal resources and abilities of an organization. Dess, et al. (2014) stated that competitive advantage is the set of resources and capabilities that enable an organization to overcome the competitive forces. Sudrajat (2015) posited that competitive advantage is the successful design and implementation of value creating strategy that competitors cannot use.

\subsubsection{Dimensions of Competitive Advantage}

Drawing on Resource-Based View (RBV) (Barney,1991), this study would suggest that a firm is said to have a competitive advantage once it acquires resources that are valuable, rare, imperfectly imitable, and organizational supported. In a narrower business context, organizations should understand how to differ themselves from other competitors in a way that could be the base for occupying a competitive position (Johnson, et al., 2016). The competitive advantage of an organization is attributed to the distinctiveness of its capabilities. Capabilities 
refer to abilities of an organization to enhance its long-term competitive advantage (Winter, 2014). The two main components of strategic capabilities are resources and competences (Wheelen, 2015). Resources are the organizational assets that can call upon, whereas competencies refer to the effective utilization of the organizational resources. When these competencies are considered as superior to current and potential competitors, they are called distinctive competencies.

\subsubsection{Value}

According to Johnson, et al. (2016), competencies are considered valuable when that develop products or services that are of value for customers. Therefore, it can be concluded that valuable competencies include three main components. First, these competencies should be exploited in order to take the advantage of opportunities and avoid threats (Hinterhuber, 2013). Second, the organizational competences should be seen valuable in the eyes of the customers. Third, the competences should allow an organization to obtain a reasonable return while reducing the cost (Hesterly and Barney, 2010).

\subsubsection{Rarity}

Competencies that are valuable but available for other competitors are unlikely to provide an organization with a competitive advantage (Johnson, et al., 2016). Therefore, organizational competences should be characterized by rarity. Rare competences are those owned uniquely by one organization or by a few other organizations. The premise behind developing rare competencies is that once the competences are become valued by customers, competitors would seek to introduce these competencies by accessing to the same technology (Barney, 1991; Wheelen, et al., 2015).

\subsubsection{Inimitability}

An organization should seek to develop competencies that are imperfectly imitable. Inimitable competences are those that other competitors find complicated and costly to duplicate, acquire, or substitute (Newbert, 2008). Strategically speaking, (Hesterly and Barney, 2010) pointed out that the barriers to duplication are deeply rooted in the organization in relationships between actions, skills and employees. Therefore, these relationships make it difficult for competitors to copy the organizational competencies (Johnson, et al., 2016; Aldalahmeh, et al., 2018).

\subsubsection{Organizational Support}

Creating value to customers and acquiring competencies that are rare and complicated to copy provides a potential for a competitive edge (Johnson, et al., 2016). However, an organization should concentrate on taking a fully competitive advantage. Therefore, it should support its strategic competencies. 
Teece and Leih (2016) defined the organizational support as the appropriate set processes and formal and informal management control system that are adopted to support the strategic competences in obtaining a competitive advantage. The organization's formal and informal functions are the backbones to protect its strategic assets.

\subsection{Intellectual Capital and Competitive Advantage}

Scholars and practitioners are concerned with understanding the linkage between intellectual capital and competitive advantage. Accordingly, Chen (2008) conducted a study to investigate the positive effect of intellectual capital on firms' competitive advantage. The study filled a gap of not examining the intellectual capital about green innovation or environmental management of an organization. In a narrow context, the researcher argued that the continuous changes dramatically increase the industrial competition. These changes put on the shoulders of organizations a remarkable responsibility to find out solutions to enhance the corporate image, reputation, the productivity, sell the know-how and services of environmental protection. Therefore, developing a novel construct of green intellectual capital is necessary in achieving a competitive edge. Green intellectual capital consisting of green human capital, green structural capital, and green relational capital are considered the main drivers behind building a competitive advantage. In words, green human capital as composed of employees' knowledge, skills, attitudes, ethics, commitments about environmental awareness or green innovation can support an organization to gain a competitive advantage. Regarding the green structural capital, the researcher hypothesized that the organizational capabilities, culture, commitments, and processes can help an organization to occupy a competitive position. On the same hand, the green relational capital in terms of the relationships with the external stakeholders about green innovation and environmental management can lead to a competitive advantage (Duoduand Rowlinson,2016).

Scholars have moved further to better understand the nature of the relationship between intellectual capital and competitive advantage using advanced statistical tools. For instance, Kamukama (2013) investigated the linkage among intellectual capital, financial performance, and competitive advantage. The study aims to examine the mediating effect of competitive advantage on the relationship between intellectual capital and firm financial performance in Uganda microfinance institutions. The researcher suggested that intellectual capital can enhance the firms' financial performance (Abuhashesh et al., 2019c, d). Furthermore, it has been asserted that intellectual capital encompasses resources that are valuable, rare, imperfectly imitable, and non-substitutable (Guthrieand Petty, 2004; Masa'deh, 2012). 
Kamukama (2013) examined the relationship between intellectual capital and competitive advantage and argued that intellectual capital is the invisible source toward achieving a competitive advantage. What distinguishes this study is that it aims to analyze the individual contribution of intellectual capital components to competitive advantage. Therefore, it is hypothesized that intellectual capital through its main aspects has a positive influence on the firm's competitive advantage. Theoretically, the study has established that the dimensions of intellectual capital work on a synergic approach to influence the firm's competitive advantage. The study recommended to use different methodological approaches such as the interview to triangulate the data collection methods in this study. Furthermore, adapting a longitudinal approach enhance the reliability of study findings.

Clearly, the relationship between intellectual capital and competitive is extensively studied in western business settings. However, Yaseen, et al. (2016) assessed the effect of intellectual capital on competitive advantage in Jordanian telecommunication sector. They stated that organizations owned various resources that enhance their performance. these resources can be tangible or intangible. Intellectual capital as the intangible assets can be exploited to gain a sustainable competitive advantage. Data on this study was collected using a questionnaire distributed to the companies in the telecommunication sector. The multiple regression analysis revealed that the structural capital and relational capital have a positive influence on achieving a competitive advantage. It is somewhat surprising that human capital does not significantly influence the competitive advantage. The researchers proposed that presence of other variables can enhance the influence of human capital on competitive advantage.

\section{Methodology}

This research used the Statistical Package for social science (SPSS) and the Analysis of Moment Structure (AMOS) to examine the data gathered for this study. Testing study hypotheses requires determining the appropriate statistical methods (Sekaran and Bougie, 2016). Moreover, determining the appropriate statistical methods rely on the number of study variables. Thus, multivariate statistical techniques since it includes more than one independent variable (intellectual capital) to explain the variance in the dependent variable (Competitive Advantage). The population of this study consists of all employees at all managerial levels working in the three major telecommunication companies operating in Jordan (Orange, Zain, Umniah). As per to the annual reports of these companies at the end of 2016, it has been reported that the total number of employees working in the telecommunication companies was 3119 employees. Few studies analyzed the influence of intellectual capital on achieving a competitive advantage. Furthermore, this study aims to introduce additional evidence that intellectual capital through its main dimensions: human 
capital, structural capital, and relational capital enhances the chance of obtaining a competitive advantage. In this chapter, data will be presented, analyzed and interpreted. Data were collected using questionnaire as the main study instrument. 335 employees at all managerial levels in the Jordanian telecommunication sector participated in this research. Moreover, data was statistically analyzed using SPSS and AMOS. Then, descriptive statistics of the main variables and their dimensions will be presented using the arithmetic mean, standard deviation, and the ranking equation. Thereafter, to assure that the independents variables are not strongly correlated; multi co-linearity analysis was established using the variance of inflation and tolerance value (Blumberget al., 2014).

\subsection{Descriptive Statistics of the Main Variables}

The descriptive statistics present the attitudes of respondents toward the main variables in the study and the questions they were asked. To do this, the arithmetic mean, standard deviation, and the relative importance should be calculated. The Likert-scale from ( 1 to 5 ) was adapted to allow respondents to express their agreement or disagreement regarding the questions in the instrument. This scale enables the research to transform qualitative data into quantitative data. Therefore, variables can be statistically assessed.

According to the study equations, the variable within the range between ( 1 to 2.33 ) is considered low important. The variable within the range between $(2.34$ to 3.67 ) is considered moderately important, whereas, the variable within the range between ( 3.68 to 5 ) is considered highly important.

The following table presents the arithmetic mean, standard deviation, the level of importance, and the rank for main variables:

Table 1. Means and standard deviations of the main variables

\begin{tabular}{|l|l|l|l|l|}
\hline Variable & Mean & $\begin{array}{l}\text { Standard } \\
\text { Deviation }\end{array}$ & $\begin{array}{l}\text { Relative } \\
\text { Importance }\end{array}$ & Rank \\
\hline Intellectual Capital & 4.05 & 0.721 & High & 1 \\
\hline Competitive Advantage & 3.96 & 0.863 & High & 2 \\
\hline
\end{tabular}

Referring to the above table, it can be observed that the main variables are highly important for the respondents in the telecommunication companies in Jordan. In words, intellectual capital has an arithmetic mean of (4.05). This is an evidence that the majority of respondents "agree" with the questions regarding the intellectual capital. The standard deviation of intellectual capital is (0.721) which is statistically confirmed. Respondents on the competitive advantage exert positive attitude regarding the questions where the arithmetic mean is (3.96) and standard deviation is (0.863) which is relatively above the average. Further to above, the relative importance and ranks have been estimated. Intellectual 
capital has the highest level of importance, followed by competitive advantage and organizational innovation (Liao et al, 2017).

\subsection{Inferential Statistics: Hypotheses Testing}

To test these hypotheses, multiple regression analysis was conducted. Traditionally, the level of significant in the scientific business research is (0.05). Thus, the confidence level is (95\%).

$\mathrm{H}_{01}$ : Intellectual Capital has no statistical effect on Competitive Advantage.

$\mathbf{H}_{01.1}$ : Human Capital has no statistical effect on Competitive Advantage.

$\mathbf{H}_{01.2}$ : Structural Capital has no statistical effect on Competitive Advantage.

$\mathbf{H}_{01.3}$ : Relational Capital has no statistical effect on Competitive Advantage.

Table 2. Multiple regression of the first hypotheses

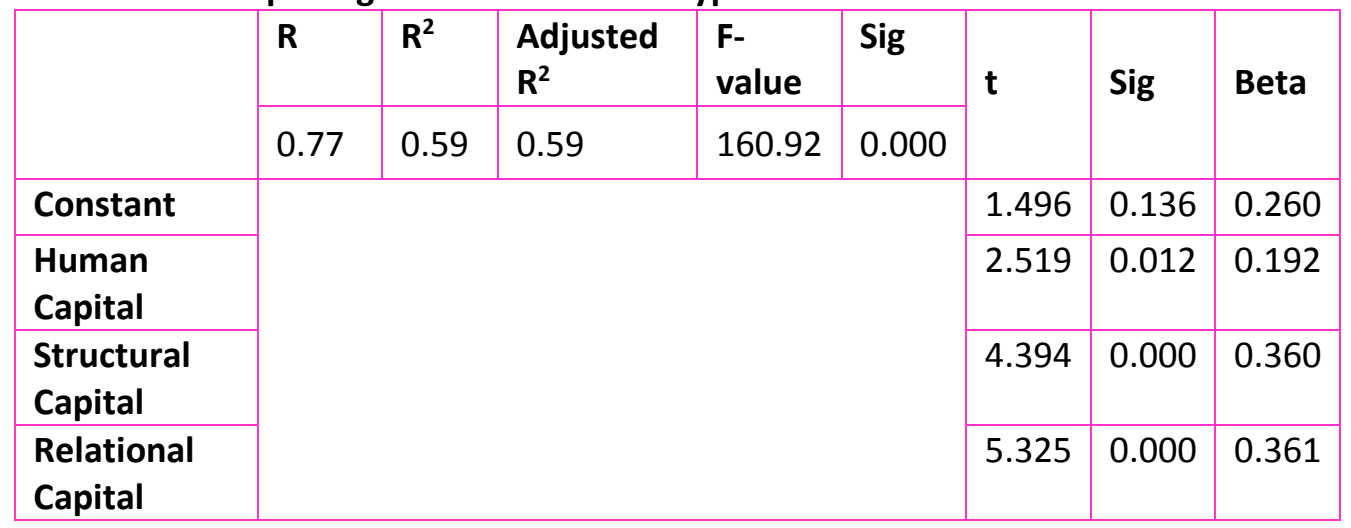

Further to the above table, it can be noticed that the multiple correlation coefficient $R$ is (0.770). This indicates a positive correlation between intellectual capital and competitive advantage. The coefficient of determination R2 is (0.593). This value presents that the tripod of intellectual capital explained $59.3 \%$ of the variation in competitive advantage. Moreover, it is evident that the adjusted R2 is (.590). If the adjusted R2 is subtracted from R2 (0.593-0.590) = 0.003 . This little shrinking $(0.003)$ proves that if the model has been fitted when the whole population participates in the study, the higher possible variance would be (0.003). The probability of F-Value (160.929) refers to the association among human capital, structural capital, and relational capital. This association has a significant effect on competitive advantage at $(\alpha \leq 0.05)$. Accordingly, the first main hypothesis is rejected.

Regarding the effect of human capital on competitive advantage, it is evident from the previous table that significant value of human capital at $(\alpha \leq 0.05)$ is (0.012). The t-calculated is (2.519) is greater than the value of t-tabulated (1.96). This proves that the human capital has a remarkable effect on competitive advantage. Therefore, the null hypothesis is rejected at $(\alpha \leq 0.05)$. 
As for the structural capital, it can be observed that structural capital has significant value of $(0.000)$ at $(\alpha \leq 0.05)$. the t-calculated is (4.394) and significantly greater than the value of t-tabulated (1.96). Based on these findings. Accordingly, the null hypothesis is rejected. Indeed, it can be argued that documenting the organizational knowledge and promoting effective culture and work system would enhance the ability to acquire a competitive advantage in the telecommunication companies.

In terms of relational capital, the previous table shows that relational capital has significant value of $(0.000)$ at $(\alpha \leq 0.05)$. The value of t-calculated is $(5.325)$ is greater than (1.96). Building on these finding, the null hypothesis is rejected. In general, enhancing the collaboration among employees to exchange ideas and build two-way communication channels to obtain clients' feedback would promote the ability of telecommunication companies to occupy a competitive position. The following table presents the decisions that can be made regarding the first null hypotheses:

Table 3. The results of testing the first null hypotheses

$\mathbf{H}_{01.1}$ : Human Capital has no statistical effect on Competitive $\quad$ Rejected Advantage.

$\mathbf{H}_{\text {01.2: }}$ Structural Capital has no statistical effect on Rejected Competitive Advantage

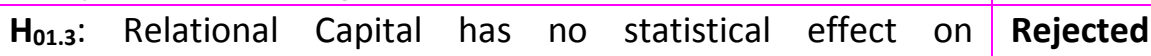
Competitive Advantage.

Consequently, the study shows that intellectual capital has a significant influence on competitive advantage where the coefficient value is (.9198).

\section{Discussion and Conclusions}

Analyzing the data collected from 335 employees' at all managerial levels working in the telecommunication sector reveals that intellectual capital significantly effects on the organizational ability in attaining a competitive advantage at $(\alpha \leq 0.05)$. This finding supported the conclusions of Yaseen, et al., (2016). Theoretically speaking, drawing on the RBV as suggested by Barney (1991), it has been stated that intellectual capital as a substantial intangible resource within an organization have a direct and indirect impact on enhancing the competitive position of the firm. Intellectual capital is considered as the combination and exchange of intellectual resources that can be presented either in an explicit or implicit knowledge. This knowledge is considered as the fundamental base in building a competitive advantage. Furthermore, RBV stressed that competitive advantage can be achieved through acquiring resources that are valuable, rare, imperfectly imitable, and organizational supported. Therefore, the organizational ability in integrating and creating a 
congruence among the intellectual component can help companies achieve competitive advantage in the telecommunication sector in Jordan.

Regarding the tripod of intellectual capital, it has been found that human capital has a significant effect on achieving a competitive advantage at $(\alpha \leq 0.05)$. Indeed, this finding is supported by somescholars (e.g. Jaradat, et al., 2012; Chahal and Bakshi, 2015). The premise behind this finding is that human capital comprises all business capabilities embedded in the individual and not owned by the organization. It is also the individual stock of an organization as represented by employees. In this context, human capital is associated with the innate ability, intelligence, creation and talent brainpower and considered as a core component of intellectual capital. Therefore, it is the main source in building a competitive advantage. As for the structural capital, it has been found that structural capital has a remarkable effect in enhancing the competitive position at $(\alpha \leq 0.05)$. This finding is supported the conclusion of Kavida and Sivakoumar (2009) work.

Structural capital includes the tacit knowledge or codified knowledge artifacts. It is considered as the pool of knowledge and the supportive infrastructure that facilitates exploiting human and relational capital. Indeed, organizations with effective structural capital can find a better harmonization among the components of intellectual capital. Therefore, it can be postulated that enhancing the structural capital is useful to achieve a sustainable competitive advantage. it has also been found that relational capital has a significant influence on achieving a competitive advantage at $(\alpha \leq 0.05)$. This finding is highly consistent with the findings of. Schiuma and Marr,(2001), Chen (2008), and Jaradat et al. (2012) who argued that among the components of intellectual capital, relational capital is considered that most favorable and influential component in achieving a competitive advantage. At its core, relational capital is concerned with the mobilization of resources and knowledge through a social structure. Thus, it can be argued that building strong ties with all stakeholders' help in achieving a competitive edge.

\subsection{Contribution of the Study}

This research was built on previous literature regarding the role of intellectual. Indeed, the findings of this study have practical and theoretical contribution in a significant way. From practical perspective, researches were conducted in different countries with different cultures and different work settings. However, this study was conduct in Jordan as one of the developing countries as limited efforts have been exerted to study the nature of this relationship in developing countries. In addition, thispaper highlights the critical role of intellectual capital on competitive advantage in such intensive based-technology as the telecommunication sector. 
From theoretical perspective, the distinguishing feature of this study is the solid theoretical framework that built on a clear methodology. In other words, intellectual capital has been assessed using the most popular tripod of human, structural, and relational capital as suggested by as (SubramaniamandYoundt, 2005; Seleim and Khalil, 2011; Dahiyat, et al., 2014). This construct achieved a high degree of acceptance among researchers as it covers the concept of intellectual capital and enhances the parsimonies of the study.

\subsection{Limitations and Recommendations}

Despite the remarkable importance of this study, it holds some limitations. These limitations should be acknowledged to help researchers fill the gaps. First, this study adopts the questionnaire as a major instrument to collect data regarding intellectual capitaland competitive advantage. Indeed, every data collection method has its own built-in biases. As for the questionnaire, respondents may have overemphasized the positive aspect of intellectual capitaland competitive advantage. Therefore, it is recommended resorting to multi-method of data collection that may help researchers to overcome these biases. Second, it has been observed that some respondents provide inconsistent and illogical answers in questionnaire. However, these respondents have been scientifically treated as suggested by Sekaran and Bougie (2016). Third, the current study employed cross-sectional survey design. The purpose of this design is to collect data that would be pertinent to addressing the answer to research question. It is advised to adapt the longitudinal survey design in future studies. A longitudinal study can provide further insight on how individuals perceive intellectual capitaland competitive advantage at more than one time. It may also show other relationships among variable at different points of testing. Fourth, the sampling design chosen in this study may influence the generalizability of the findings. Convince sampling is characterized by quick, and efficiency. However, this sampling design is the least reliable of all sampling designs regarding the generalizability. To overcome this limitation, it is recommended to use other probability sampling techniques as simple random or stratified random sampling to obtain more useful and generalized findings. Finally, this research was conducted in the Jordanian telecommunication sector as one of the most competitive sectors in Jordan (Abuhashesh et al., 2019a). It is recommended to conduct this research in other sectors as the banking or pharmaceutical sectors. Also, it is advisable to represent the importance of this study by conducting this research at the country level. From theoretical point of view, the current study concentrates on the three dimensions of intellectual capital namely, human capital, structural capital, and relational capital. Other intellectual capital dimensions are recommended to be used in measuring the importance of intellectual capital (Ding, 2010). 
From practical point of view, managers in the telecommunication companies should be aware about the importance of exploiting the intellectual resources as they have a crucial influence on attaining a competitive advantage. it is also important for the telecommunication companies to comprehend the vital role of intellectual capital in achieving a sustainable competitive advantage. Therefore, this puts on the shoulders of managers in the telecommunication companies a huge responsibility to improve performance by investing more resources in human capital, relational capital and structural capital (Al-Syaidh et al., 2016; Barney et al,. 2016; Abuhashesh et al., 2019b). Moreover, in a swiftly moving world, the telecommunication companies should encourage employees with the tacit or intangible knowledge that in their heads as it tremendously helps firms to create valuable goods and services.

\section{References}

Abualoush, S., Bataineh, K., \& Alrowwad, A. (2018a).The role of knowledge management process and intellectual capital as intermediary variables between knowledge management infrastructure and organization performance. Interdisciplinary Journal of Information, Knowledge, and Management, 13, 279309.

Abualoush, S., Obeidat, A., \& Tarhini, A. (2018b). The role of employees' empowerment as an intermediary variable between knowledge management and information systems on employees' performance. VINE Journal of Information and Knowledge Management Systems, 48(2), 217-237.

Abuhashesh, M., Al-Dmour, R., \& Masa'deh, R. (2019a). Factors that affect employees job satisfaction and performance to increase customers' satisfactions. Journal of Human Resources Management Research, 1-23.

Abuhashesh, M., Al-Dmour, R., \& Masa'deh, R. (2019b). Factors that impact job satisfaction and performance among employees in the Jordanian industrial sector. Proceedings of the 32nd International Business Information Management Association Conference, IBIMA 2018-Vision 2020: Sustainable Economic Development and Application of Innovation Management from Regional expansion to Global Growth, 4285-4305.

Abuhashesh, M., Al-Khasawneh, M., \& Al-Dmour, R., (2019c). The impact of Facebook on Jordanian consumers' decision process in the hotel selection. IBIMA Business Review, 1-16.

Abuhashesh, M., Mohammad, S.J., \& Al Khasawneh, M. (2019d). The attitude of Jordanian customers towards virtual stores. Int. J. Islamic Marketing and Branding, 4(1), 59-75. 
Al-dalahmeh, M., Khalaf, R., \& Obeidat, B. (2018). The effect of employee engagement on organizational performance via the mediating role of job satisfaction: The case of IT employees in Jordanian banking sector. Modern Applied Science, 12(6), 17-43.

Al-Dmour, R., Obeidat, B., \& Almajali, D. (2015). The practice of HRIS applications in business organizations in Jordan: An empirical study. 4th Scientific \& Research Conference on New Trends in Business, Management and Social Sciences (COES\&RJ-TK15/1).

Al-Syaidh, N., Al- Lozi, M., \& AlHarrasi, J. (2016). Transformational leadership and its role on the effectiveness of employees' behavior: A theoretical study. Journal of Business \& Management (COES\&RJ-JBM), 4(1), 14-35.

Amiri, A.N., Jandghi, G., Alvani, S.M., Hosnavi, R., \& Ramezan, M. (2010). Increasing the intellectual capital in organization: Examining the role of organizational learning. European Journal of Social Sciences, 14(1), 98-108.

Barney, J. (1991). Firm resources and sustained competitive advantage. Journal of Management, 17(1), 99-120.

Barney, J.B., \& Turk, T.A. (2016). 5 superior performance from implementing merger and acquisition strategies: A resource-based. The Management of Corporate Acquisitions: International Perspectives, 105.

Blumberg, B., Cooper, D.R.,\& Schindler, P.S. (2014). Business Research Methods (4th ed). United States: McGraw Hill Higher Education

Bontis, N. (1998). Intellectual capital: An exploratory study that develops measures and models. Management Decision, 36(2), 63-76.

Chahal, H., \& Bakshi, P. (2014). Effect of intellectual capital on competitive advantage and business performance: Role of innovation and learning culture. International Journal of Learning and Intellectual Capital, 11(1), 52-70.

Chahal, H., \& Bakshi, P. (2015). Examining intellectual capital and competitive advantage relationship: Role of innovation and organizational learning. International Journal of Bank Marketing, 33(3), 376-399.

Chen, Y.S. (2008). The positive effect of green intellectual capital on competitive advantages of firms. Journal of Business Ethics, 77(3), 271-286. 
Ding, Y. (2010). Study on the management of intellectual capital. International Journal of Business and Management, 5(2), 213.

Duodu, B., \& Rowlinson, S. (2016, June). Intellectual capital and innovation in construction organizations: A conceptual framework. In the Engineering Project Organization Conference (EPOC2016).

Dženopoljac, V., Janoševic, S., \& Bontis, N. (2016). Intellectual capital and financial performance in the Serbian ICT industry. Journal of Intellectual Capital, 17(2), 373-396.

Edvinson, L.M. (1997). MS, intellectual capital: Realizing your company's true value by finding it's hidden roots.

European Commission (2006a). Innovation policy in a knowledge-based economy, Merit Study commissioned by the European Commission Enterprise Directorate General, EUR 17023, available at: www.cordis.lu/innovationsmes/src/studies.html

Grimaldi, M., Cricelli, L., \& Rogo, F. (2012). A methodology to assess value creation in communities of innovation. Journal of Intellectual Capital, 13(3), 305330.

Guthrie, J., Petty, R.M., \& Ricceri, F. (2004). External intellectual capital reporting: Contemporary evidence from Hong Kong and Australia.

Hall, R. (1992). The strategic analysis of intangible resources. Strategic Management Journal, 13(2), 135-144.

Hesterly, W., \& Barney, J. (2010). Strategic management and competitive advantage. Upper Saddle River, NJ.

Hinterhuber, A. (2013). Can competitive advantage be predicted? Towards a predictive definition of competitive advantage in the resource-based view of the firm. Management Decision, 51(4), 795-812.

Hsu, L.C., \& Wang, C.H. (2012). Clarifying the effect of intellectual capital on performance: The mediating role of dynamic capability. British Journal of Management, 23(2), 179-205.

Jaradate, O.M., Al-Samralie, F.A., \& Jadallah, N.A. (2012). Intellectual capital and its role in achieving competitive advantage: A field study for the Jordanian income tax service. European Journal of Scientific Research, 69(3), 399-415. 
Johnson, G., Scholes, K., \& Whittington, R. (2016). Exploring corporate strategy: Text and cases. Pearson Education.

Kamukama, N. (2013). Intellectual capital: Company's invisible source of competitive advantage. Competitiveness Review: An International Business Journal, 23(3), 260-283.

Kavida, V., \& Sivakoumar, N. (2009). Intellectual capital: A strategic management perspective. IUPJournal of Knowledge Management, 7(5/6), 55.

Karajeh, H., \& Maqableh, M. (2014). Security of cloud computing environment. Proceedings the 23rd IBIMA Conference on Vision 2020: Sustainable Growth, Economic Development, and Global Competitiveness, 2202-2215.

Li, Q., \& Chang, C. (2010). The customer lifetime value in Taiwanese credit card market. African Journal of Business Management, 4(5), 702.

Liao, S.S., Chen, C.C., Hu, D.C., Chung, Y.C., \& Liu, C.L. (2017). Assessing the influence of leadership style, organizational learning and organizational innovation. Leadership \& Organization Development Journal, 38(5).

Ma, H. (2004). Toward global competitive advantage: Creation, competition, cooperation, and co-option. Management Decision, 42(7), 907-924.

Makadok, R. (2010). The interaction effect of rivalry restraint and competitive advantage on profit: Why the whole is less than the sum of the parts. Management Science, 56(2), 356-372.

Manzaneque, M., Ramírez, Y., \& Diéguez-Soto, J. (2017). Intellectual capital efficiency, technological innovation and family management. Innovation, 19(2), 167-188.

Maqableh, M., Rajab, L., Quteshat, W., \& Khatib, T. (2015). The impact of social media networks websites usage on students' academic performance. Communications and Network, 7(4), 159-171.

Marr, B. (2004). Measuring and benchmarking intellectual capital. Benchmarking: An International Journal, 11(6), 559-570.

Masa'deh, R. (2012). The impact of management information systems (MIS) on quality assurance (QA): A case study in Jordan. International Journal of Information, Business and Management, 4(2), 93-110. 
Masa'deh, R., Obeidat, B., Zyod, D., \& Gharaibeh, A. (2015). The associations among transformational leadership, transactional leadership, knowledge sharing, job performance, and firm performance: A theoretical model. Journal of Social Sciences (COES\&RJ-JSS), 4(2), 848-866.

Mehralian, G., Rasekh, H.R., Akhavan, P., \& Ghatari, A.R. (2013). Prioritization of intellectual capital indicators in knowledge-based industries: Evidence from pharmaceutical industry. International Journal of Information Management, 33(1), 209-216.

Mertins, K., Alwert, K., \& Will, M. (2006, September). Measuring intellectual capital in European SME. In Proceedings of I-Know (Vol. 6, pp. 6-8).

Newbert, S.L. (2008). Value, rareness, competitive advantage, and performance: A conceptual-level empirical investigation of the resource-based view of the firm. Strategic Management Journal, 29(7), 745-768.

Obeidat, B., Tarhini, A., \& Aqqad, N. (2017). The impact of intellectual capital on innovation via the mediating role of knowledge management: A structural equation modelling approach. International Journal of Knowledge Management Studies, 8(3-4), 273-298.

Porter, M.E. (2008). Competitive advantage: Creating and sustaining superior performance. Simon and Schuster.

Putnam, R.D. (1995). Tuning in, tuning out: The strange disappearance of social capital in America. PS-WASHINGTON-, 28, 664-664.

Rocha, E.A. (2012). The impact of the business environment on the size of the micro, small and medium enterprise sector: Preliminary findings from a crosscountry comparison. Procedia Economics and Finance, 4, 335-349.

Rodrigues, L.L., Tejedo-Romero, F., \& Craig, R. (2017). Corporate governance and intellectual capital reporting in a period of financial crisis: Evidence from Portugal. International Journal of Disclosure and Governance, 14(1), 1-29.

Schiuma, G., \& Marr, B. (2001). Measuring and managing intellectual capital and knowledge assets in new economy organizations. Bourne M., Performance Measurement Handbook, GEE Publishing Ltd.

Sekaran, U., \& Bougie, R.J. (2016). Research methods for business: A skill building approach. John Wiley and Sons. 
Seleim, A.A., \&Khalil, O.E. (2011). Understanding the knowledge managementintellectual capital relationship: a two-way analysis. Journal of Intellectual Capital, 12(4), 586-614.

Sharabati, A.A., Nour, A.N., \& Shamari, N.S. (2013). The impact of intellectual capital on Jordanian telecommunication companies' business performance. American Academic \& Scholarly Research Journal, 5(3 special issue), 32.

Sofian, S., Tayles, M., \& Pike, R.H. (2004). Intellectual capital: An evolutionary change in management accounting practices. University of Bradford, School of Management.

Stewart, T. (1997). Intellectual capital: The new wealth of organizations. New York: Doubleday Dell Publishing Group.

Subramaniam, M., \& Youndt, M.A. (2005). The influence of intellectual capital on the types of innovative capabilities. Academy of Management Journal, 48(3), 450-463.

Sudrajat, D. (2015). Competitiveness improvement of Indonesian logistics service providers: A conceptual model and future research framework. Advanced Science Letters, 21(4), 1049-1052.

Teece, D., Peteraf, M., \& Leih, S. (2016). Dynamic capabilities and organizational agility: Risk, uncertainty, and strategy in the innovation economy. California Management Review, 58(4), 13-35.

Wang, Z., Wang, N., \& Liang, H. (2014). Knowledge sharing, intellectual capital and firm performance. Management Decision, 52(2), 230-258.

Wheelen, T.L., Hunger, J.D., Hoffman, A.N., \& Bamford, C.E. (2015). Strategic management and business policy: Globalization, innovation, and sustainability, Global Edition.

Winter, S.G. (2014). The future of evolutionary economics: Can we break out of the beachhead?. Journal of Institutional Economics, 10(4), 613-644.

Yaseen, S.G., Dajani, D., \& Hasan, Y. (2016). The impact of intellectual capital on the competitive advantage: Applied study in Jordanian telecommunication companies. Computers in Human Behavior, 62, 168-175. 